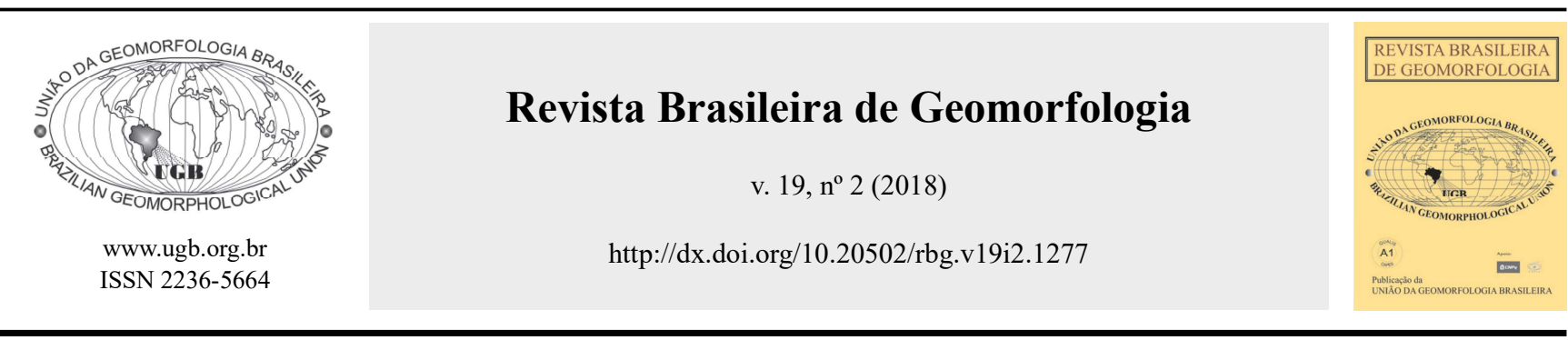

\title{
DISTRIBUIÇÃO E TRANSPORTE DE SEDIMENTOS COSTEIROS EXEMPLOS EM ARRAIAL DO CABO, RJ
}

\author{
DISTRIBUTION AND TRANSPORT OF COASTAL SEDIMENTS \\ EXAMPLES IN ARRAIAL DO CABO, BRAZIL
}

Paula Rohan da Motta

Instituto de Ciências da Sociedade e Desenvolvimento Regional, Universidade Federal Fluminense Rua José do Patrocínio, 71, Campos dos Goytacazes, Rio de Janeiro. CEP: 28015-385. Brasil Email: paularohan@id.uff.br

Laura Rangel Netto

Instituto de Ciências da Sociedade e Desenvolvimento Regional, Universidade Federal Fluminense Rua José do Patrocínio, 71, Campos dos Goytacazes, Rio de Janeiro. CEP: 28015-385. Brasil

Email: laurarangel@id.uff.br

Eduarda Bulhões Bastos

Instituto de Ciências da Sociedade e Desenvolvimento Regional, Universidade Federal Fluminense Rua José do Patrocínio, 71, Campos dos Goytacazes, Rio de Janeiro. CEP: 28015-385. Brasil Email:eduardabastos@id.uff.br

Thiago Gonçalves Pereira

Instituto de Geografia, Universidade do Estado do Rio de Janeiro Rua São Francisco Xavier, 524, Rio de Janeiro, Rio de Janeiro. CEP: 20550-013. Brasil

Email: thiagopereira.uerj@gmail.com

Eduardo Manuel Rosa Bulhões

Instituto de Ciências da Sociedade e Desenvolvimento Regional, Universidade Federal Fluminense Rua José do Patrocínio, 71, Campos dos Goytacazes, Rio de Janeiro. CEP: 28015-385. Brasil

Email:eduardobulhoes@id.uff.br

\section{Informações sobre o Artigo}

Recebido (Received):

14/07/2017

Aceito (Accepted):

$14 / 02 / 2018$

Palavras-chave:

Granulométrica; Depósitos

Costeiros; Praias de Enseada.

\section{Keywords:}

Grain Size Trend Analysis; Coastal Deposits; Bayhead Barrier Beaches.

\section{Resumo:}

O trabalho discute temas relacionados à distribuição de sedimentos costeiros, parâmetros granulométricos e modelos bidimensionais de transporte de sedimentos. Parte-se da hipótese de que a disposição dos materiais na superfície de fundo das enseadas permite o diagnóstico de processos associados à hidrodinâmica marinha e sua participação no controle do transporte e distribuição dos sedimentos costeiros. O objetivo central é então caracterizar a textura superficial do depósito costeiro e apresentar correlações entre os parâmetros estatísticos que permitam o diagnóstico de processos relacionados à distribuição e ao transporte dos sedimentos no sistema praia-antepraia. Como área de pesquisa, foram selecionadas três enseadas no município de Arraial do Cabo (RJ). As etapas metodológicas partiram da definição de uma malha amostral, coleta de 96 amostras de sedimentos em profundidades entre 1 e 23 metros, seguido por análises granulométricas em 
laboratório, determinação de parâmetros estatísticos e cálculo do modelo de tendências de transporte de sedimentos (GSTA). Os resultados apontam a ocorrência majoritária de areias finas (41,6\%) e médias (17,7\%) moderadamente bem selecionadas como o principal depósito nas enseadas, no entanto, além dos depósitos palimpsestos, núcleos de deposição de areias grossas $(14,6 \%)$ e muito grossas $(8,3 \%)$ e, por outro lado, areias muito finas $(5,2 \%)$ e siltes $(6,2 \%)$ também foram identificados e discutidos à luz de sua significância ambiental. Quanto ao modelo de transporte, o melhor ajuste $(65 \%)$ foi feito com o padrão $\mathrm{FB}$, que indica sedimentos mais finos e mais bem selecionados na direção do transporte. Conclui-se que os depósitos palimpsestos são responsáveis pelo abastecimento da praia emersa e que os esforços de interpretação dos parâmetros estatísticos e a geração de resultados de transporte de sedimentos a partir de modelos não hidrodinâmicos geram informações úteis, dentre outras, para o diagnóstico de erosão costeira, para a temática ambiental, para calibrar modelos hidrodinâmicos de transporte de sedimentos e para a determinação de processos governantes da agitação oceânica em praias e suas resultantes morfossedimentares.

\begin{abstract}
:
This paper discusses issues related to coastal sediments distribution, grain size parameters and two - dimensional models of sediment transport. The hypothesis is that sedimentary materials arranged on the bottom of the coves allows the diagnosis of processes associated with marine hydrodynamics and their control on the pattern of sediment distribution and transport. The main goal is to characterize the surface texture of the coastal deposit and propose correlations between statistical parameters that are diagnostic of the processes associated to the distribution and transport of sediments in the shoreface. As a research area, we selected three coves in Arraial do Cabo, a small coastal town in Rio de Janeiro, Brazil. The methodological steps started with a mesh defined for collect 96 sediment samples ranging from depths between 1 and 23 meters, followed by laboratory analysis, determination of statistical parameters and calculation of sediment transport trends model (GSTA). The results point that fine sands (41.6\%) and medium sands (17.7\%), moderately well sorted are the main deposit in the coves. However, in addition to palimpsest deposits, very fine sands (5.2\%) and silts (6.2\%) were also identified and discussed in the light of their environmental significance. As for the transport model, the FB standard had the best adjustment (65\%), which indicates finer and better-sorted sediments in the transport direction. The conclusion is that the palimpsest deposits are responsible for the supply of the beach in the coves and the efforts of interpretation of statistical parameters and sediment transport results from non-hydrodynamic models generate useful information, among other things, for diagnosis of coastal erosion, for environmental issues, to calibrate hydrodynamic models of sediment transport and to figure out the governing processes of the oceanic agitation in beaches and their resulting morphosedimentary forms.
\end{abstract}

\section{Introdução}

Em ambientes litorâneos, quase todos os sedimentos distribuídos por praias, estuários e plataforma continental têm origem terrígena. A distribuição dos sedimentos superficiais desde a plataforma continental interna até a praia é resultante do retrabalhamento da sedimentação pretérita e, eventualmente, da sedimentação terrígena atual submetidos aos mecanismos de transporte governantes. Ingle $\mathrm{Jr}$ (1966) identifica esse como o segmento do litoral onde é transportado o maior volume de sedimentos por unidade de tempo. De acordo com Dias (2004), seguindo a sistematização de McManus (1975), considerando a sedimentação superficial, têm-se: sedimentos neotéricos, ajustados às condições hidrodinâmicas em curso e com o aporte atual de material particulado; sedimentos relíquia, ajustados a uma condição pretérita do nível médio do mar; e os sedimentos palimpsestos, função do retrabalhamento de depósitos relíquia submetidos aos processos hidrodinâmicos atuais, apresentando, em sua composição, misturas com sedimentos neotéricos.

As fontes atuais de sedimentos para a zona costeira são citadas na literatura como sendo de origem fluvial (por meio da descarga sólida dos rios), da erosão de falésias, do carreamento a partir do retrabalhamento da porção submersa das barreiras arenosas e da plataforma continental interna, da abrasão de organismos bioincrustrados em costões rochosos e em afloramentos de recifes de corais e do transporte costa afora processado por mecanismos eólicos, ou ainda, por erosão de praias e dunas costeiras (KOMAR, 1976; DAVIS JR, 1985; MORTON; GIBEAUT; PAINE, 1995; SHORT, 1999; MASSENLINK; HUGHES, 2003).

O padrão de distribuição de sedimentos na zona submarina relaciona-se também aos aspectos evolutivos, em escala geológica, e em relação às flutuações do nível do 
mar, conjugado com ação de ondas e demais mecanismos que promovem o transporte de sedimentos junto ao fundo, elementos fundamentais na dinâmica costeira (DIAS, 2004). Ainda de acordo com Dias (2004), a caracterização do depósito sedimentar permite deduzir indicações sobre a disponibilidade de determinados tipos de partículas, as rochas fonte, os padrões de transporte de sedimentos e a acumulação nos ambientes deposicionais. Trabalhos clássicos da literatura estrangeira são usualmente utilizados como referência, dentre eles, destacam-se experimentos associados à utilização e correlação entre parametrização estatística (KRUMBEIN; PETTIJOHN, 1938; INMAN, 1949; FOLK; WARD, 1957) e modelos de transporte de sedimentos (PASSEGA, 1964; MCLAREN, 1981; MCLAREN; BOWLES, 1985) e suas interpretações ambientais (FOLK; WARD, 1957; SAHU, 1964).

Nesse contexto, o objetivo geral do artigo é caracterizar a textura superficial do depósito costeiro das enseadas de Arraial do Cabo (RJ) e apresentar correlações entre os parâmetros estatísticos que permitam diagnosticar mecanismos associados à distribuição e ao transporte de sedimentos no sistema praia-antepraia.

\section{Praias de Enseada e Dinâmica Sedimentar}

Praias de enseada são depósitos arenosos delimitados por margens rochosas ou estruturas artificiais. Em planta, a curvatura é definida pela disponibilidade de sedimentos e pelo padrão hidrodinâmico de circulação (BULHÕES et al 2014; BULHÕES; FERNANDEZ, 2016). A ocorrência de praias de enseada está usualmente associada a litorais rochosos. De acordo com Inman e Nordstrom (1971), Emery e Kuhn (1982) e Van Rijn (1998), estima-se que ocorrem entre $50 \%$ e $80 \%$ de toda a linha litorânea mundial. Estão sujeitas a uma ampla gama de processos dinâmicos, sobretudo na distribuição longitudinal e transversal de sedimentos, processos rotacionais e células de circulação induzidas por ondas.

O efeito das ondas atacando obliquamente uma praia é o desenvolvimento de fluxos longitudinais, e o resultado morfológico em planta é uma assimetria na direção preferencial do transporte. Os processos mais relevantes foram destacados por Short e Masselink (SHORT, 1999), que, através de um parâmetro adimensional, identificaram o impacto de ondulações na configuração de processos dinâmicos em enseadas. Para esses autores, quando o tipo de circulação é denominado celular, há o predomínio da circulação longitudinal, com correntes de retorno ocorrendo nas extremidades das enseadas e o resultado morfológico é uma topografia ajustada a esses padrões.

De acordo com Klein (2004), estudos de processos litorâneos em praias de enseada estão usualmente direcionados para sistemas de circulação costeira e transporte de sedimentos. O autor apresenta pesquisa de nomenclatura e revela inúmeras denominações em língua inglesa, a saber: zeta curved bays; logarithmic spiral beaches; crenulated shaped bays; curved beaches; pocket beaches; headland bay beaches, dentre outras. Essas denominações estão normalmente relacionadas à curvatura em planta, à disposição dos promontórios rochosos e ao melhor modelo matemático que as descreve. Neste trabalho, são denominadas praias de enseada, da mesma forma que Leatherman (1988) descreve bayhead barriers, com destaque para a existência do que Short (1999) e Klein (2004) chamam de end-effects, ou seja, efeitos dos promontórios rochosos no controle das feições e na dinâmica sedimentar no sistema praia-antepraia.

\section{Modelos de Transporte de Sedimentos com Base em Parâmetros Granulométricos}

A parametrização estatística com base na granulometria dos sedimentos costeiros considera a distribuição de medidas de tendência central e de dispersão. Quanto aos parâmetros de tendência central, a média sempre existe, tem valor único, é sensível à presença de valores extremos (LANDIM, 2003), descreve a energia cinética média do agente deposicional (SAHU, 1964) e é útil para comparar amostras coletadas na direção de transporte ao longo de uma praia (KRUMBEIN; PETTIJOHN, 1938). O parâmetro mediana é considerado como o que melhor descreve os depósitos sedimentares (MUEHE, 1995; PONÇANO; GIMENEZ; FULFARO, 1976), pois oferece a vantagem de não ser afetado por valores extremos. Quanto aos parâmetros de dispersão, o desvio padrão indica a dispersão da amostra em relação ao diâmetro médio (MUEHE, 1995) e, para Sahu (1964) e Komar (1976), indica as variações na energia cinética média do agente deposicional, descrevendo uma relação inversa com o grau de selecionamento das amostras. A assimetria, que pode ser positiva ou negativa, é o grau de desvio de uma curva no sentido horizontal (ANDRIOTTI, 2003), mede a distribuição da frequência e a posição da média em relação à mediana (SAHU, 1964) apontando ainda se a curva é ou não assimétrica. Quando assimétrica, pode inclinar-se para o lado das frações finas (positiva) ou das frações grossas (negativa). Já a curtose é a medida de esbeltez ou achatamento da curva de distribuição de frequências, e, para tal, é necessária a comparação do selecionamento entre os $50 \%$ e os $90 \%$ centrais da curva (MUEHE, 1995). Designa-se como leptocúrtica a 
curva com um pico elevado, platicúrtica a curva achatada e mesocúrtica a situação intermediária (BULHÕES; ESTRADA, 2011).

De acordo com Gao (1995), foi Russel (1939) o primeiro a identificar relações entre parâmetros estatísticos e transporte de sedimentos e para o autor são três os motivos que levam à formação de um padrão na distribuição granulométrica: (a) abrasão de partículas de sedimentos; (b) selecionamento hidráulico ou transporte diferencial; e (c) mistura de materiais de diferentes fontes. McLaren (1981) foi pioneiro ao sugerir que a média, o desvio padrão e a assimetria de uma distribuição amostral seguem um padrão que indica a direção de transporte e o processo de selecionamento na deposição. Esse modelo sugere que o sedimento em transporte deve ser mais fino (F), mais bem selecionado (B) e mais negativamente (-) assimétrico do que a sua origem. Já o depositário de origem deve ser composto cada vez mais por grãos grossos $(\mathrm{C})$, mais bem selecionados (B) e positivamente $(+)$ assimétricos. Esses dois padrões podem ser identificados respectivamente por FB- e CB+. McLaren e Bowles (1985) apresentam um coeficiente de transferência indicando que, gradualmente, na direção do transporte, os sedimentos tendem a se tornar mais finos $(\mathrm{F})$ e mais negativamente assimétricos (-) do que a sua fonte. Ainda para estes últimos, o padrão de selecionamento dependeria da distribuição inicial dos sedimentos da fonte, e, na direção de transporte, o sedimento tende a ser mais bem selecionado (B). Esses dois modelos de transporte são os chamados unidimensionais.

Já os modelos bidimensionais são chamados de GSTA (Grain Size Trend Analysis) e incorporam a distância entre as amostras para representar a escala espacial na análise e vetores que identificam o grau de confidência. Gao e Collins (1991) foram os pioneiros em testes utilizando a dimensão espacial. Le Roux (1994) também propôs avanços nesse sentido para a composição dos vetores de confidência. Gao e Collins (1992 e 1994) desenvolveram o método dos vetores, assumindo que o padrão usado para as análises apresenta maior probabilidade de ocorrência de transporte residual em uma direção, a despeito das outras. Gao (1996) apresenta um modelo GSTA em linguagem FORTRAN que assume determinadas interrelações entre os parâmetros diâmetro médio, assimetria e desvio padrão para calcular a direção mais provável do transporte de sedimentos. Nesse modelo, amplamente utilizado, a partir de uma malha de sedimentos coletados, comparam-se os parâmetros de cada amostra com os seus vizinhos próximos e, na situação mais comum, o vetor será criado a partir da amostra com melhor selecionamento em direção àquela com pior selecionamento, para um mesmo diâmetro médio. Mais recentemente, Le Roux e Rojas (2007), McLaren et al. (2007) e Poizot, Mear e Biscara (2008) discutem e apresentam o estado da arte dos modelos GSTA e servem de aprofundamento para o tema. Poizot e Méar (2010) propõem a extensão GISEDTREND no qual o modelo bidimensional de tendências de transporte de sedimentos é incorporado a um ambiente de sistema de informação geográfica.

O esforço de interpretação dos parâmetros estatísticos extraídos de amostras granulométricas em sedimentos de fundo para a caracterização dos depositários e, em alguns casos, para a inferência sobre o transporte de sedimentos, não é recente. As aplicações práticas de tais estudos no Brasil aparecem usualmente para a caracterização do meio físico em Estudos e Relatórios de Impacto Ambiental e, sobretudo, em relatórios técnicos para soluções de engenharia costeira (ex. ROSMAN; VALENTINI, 1988; ROSMAN; NEVES; MELO, 1992); para a instalação de portos (ex. PONÇANO; GIMENEZ; FULFARO, 1976); para a identificação de jazidas minerais a serem usadas para a alimentação artificial de praias (ex. VERACRUZ, 1972; OLIVEIRA; MUEHE, 2013); para a caracterização da plataforma continental (ex. MUEHE; SHUCAROV, 1981; MUEHE; BARBOSA, 1982; MUEHE; CARVALHO, 1983; SAAVEDRA; MUEHE, 1994) e de paleoambientes; para a identificação de características ecológicas (ex. TOMMASI, 1969; BRONNIMANN, MOURA e DIAS-BRITO, 1981; MADEIRA; CARVALHO, 1982; MEDEIROS, 1992; MUEHE; SILVA, 1996; MAHIQUES et al., 2004); para ensaios e modelos de instrumentação geofísica (ex. SANTANA; NETO, 2015); e para a validação de modelos hidrodinâmicos. No litoral do Rio de Janeiro, parte significativa da plataforma continental interna e dos ambientes de praia e antepraia já foi investigada sob essa ótica (ver OLIVEIRA; MUEHE, 2003), no entanto lacunas de maior resolução ainda existem e, como tais, as enseadas de Arraial do Cabo foram o objeto desta contribuição.

Sobre a dinâmica morfossedimentar em praias de enseada, não são muitos os trabalhos que tratam especificamente dessa temática, apesar de o litoral do Rio de Janeiro apresentar centenas delas. São eles: Bulhões e Estrada (2011) para a enseada da Ferradura; Estrada e Bulhões (2010) para a enseada da praia Brava; 
Tavares, BULHÕES e Estrada (2010) para a enseada de Manguinhos, todas em Armação dos Búzios, RJ; e Bulhões et al. $(2014 ; 2016)$ para as enseadas entre Arraial do Cabo e Armação dos Búzios, RJ; Quadros et al. (2016) para a praia do Farol e Savi (2007) para a praia dos Anjos, ambas também em Arraial do Cabo, RJ; Silva et al. (2016) para as praias e enseadas da Baía de Guanabara, RJ; e Mahiques e Furtado (1989) para as enseadas da Baía da Ilha Grande, RJ.

\section{Aspectos Físicos da Área de Estudo}

As enseadas de Arraial do Cabo e suas praias fazem parte de um segmento de transição do litoral fluminense. Regionalmente a linha de costa, cuja orientação principal é de oeste-leste, junto à ilha do Cabo Frio se inflexiona para sudeste-noroeste e depois passa para a orientação geral de sudoeste-nordeste. De acordo com Muehe (1998), a reorientação geral da linha de costa, também percebida pelas linhas batimétricas da plataforma continental entre a Marambaia e o Cabo Frio, se deve à zona de fratura do Rio de Janeiro. Esta posição também marca a transição das bacias sedimentares de Santos para a de
Campos. Regionalmente, a área de estudo está inserida no Domínio Tectônico de Cabo Frio, definido por Schmitt et al. (2016) como uma margem continental reativada em repetidos eventos extensionais e convergentes formada por um embasamento paleoproterozoico intercalado tectonicamente em rochas supracrustrais do Neoproterozoico em contato com o orógeno Ribeira na costa sudeste do Brasil. Adicionalmente Mizusaki e Thomaz-Filho (2004) indicam que o Alto de Cabo Frio, não aflorante, caracteriza-se por derrames de rochas magmáticas associados a rochas vulcano-sedimentares de composição levemente alcalina e foram individualizados em três sequências de idade: Eocretácea (basaltos); Campaniana-Turoniana (também basaltos); e entre o Paleoceno superior e o Eoceno (basaltos, diabásios e rochas vulcanoclásticas). Localmente, a litologia indicada na Folha Cabo Frio (SCHMITT et al., 2009) para o Complexo Região dos Lagos indica, para as enseadas em questão, a ocorrência de ortognaisses de composição tonalítica a granítica o que resulta na ocorrência de areias majoritariamente quartzosas encontradas na área de estudo.

\section{Mapa de Localização e Malha Amostral}
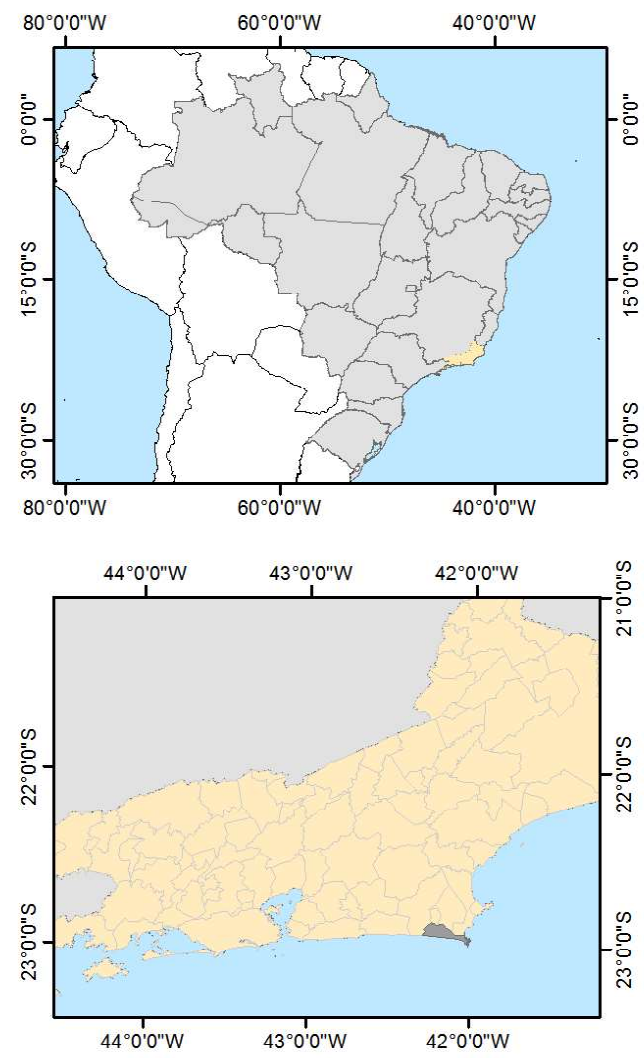

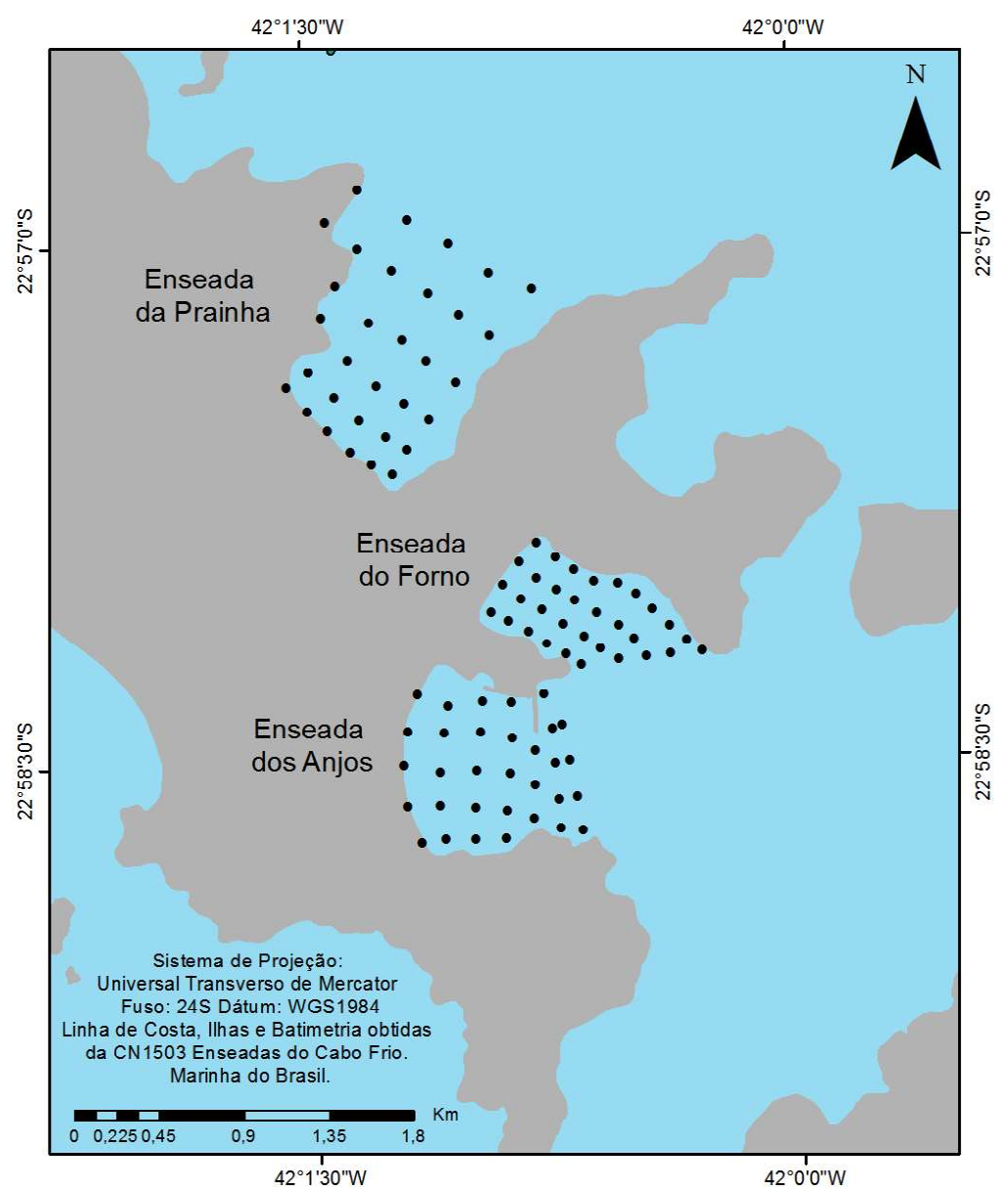

Figura 1 - Mapa de Localização e Grade Amostral de Sedimentos Coletados nas Enseadas de Arraial do Cabo-RJ. 
Quanto aos aspectos meteoceanográficos, de acordo com dados de Bulhões et al. (2014), atualizados para este trabalho (dados entre 2003 e 2017), os ventos para esta área incidem provenientes das direções entre o norte e o leste durante $68 \%$ com velocidades de até $5 \mathrm{~m} / \mathrm{s}$ durante $60 \%$ do intervalo. A média da altura significativa de ondas é de $1,6 \mathrm{~m}$ com períodos de $9 \mathrm{~s}$, ocorrendo durante $53,5 \%$ do intervalo, provenientes do quadrante entre o norte e o leste; e durante $45,5 \%$ do intervalo entre as direções sudeste e sudoeste. Essas condições são concordantes com as já amplamente descritas na literatura, como em Barbiéri (1984), Melo (1993), Parente (1999), Pinho (2003), Campos (2009), Pianca, Mazzini e Siegle (2010), dentre outros. Quanto às oscilações maregráficas, de acordo com a Marinha do Brasil (Carta Náutica 1503), classificam-se como semidiurnas com desigualdades diurnas. A média da máxima altura máxima da maré
(MHHW) é de $1,2 \mathrm{~m}$ e a média da mínima altura mínima (MLLW) é de $0,1 \mathrm{~m}$.

Especificamente para cada enseada em análise, as características morfométricas são: (a) Enseada dos Anjos: arco praial majoritariamente orientado para leste (Figura 2a) e medindo, de acordo com Savi (2007), aproximadamente $1.200 \mathrm{~m}$ com corda de $1.075 \mathrm{~m}$, onde foi construído um quebra-mar de rochas que fecha parcialmente a entrada da enseada, ocupando cerca de $35 \%$ da seção transversal. Existe nítida assimetria no volume de areias da praia emersa que é deficitário ao sul; (b) Enseada do Forno: arco praial majoritariamente orientado para a sudeste (Figura 2b) medindo aproximados $625 \mathrm{~m}$ com corda de 580m; (c) Enseada da Prainha: arco praial majoritariamente orientado para nordeste (Figura 2c) medindo, em comprimento, aproximados $910 \mathrm{~m}$ com corda de $885 \mathrm{~m}$.
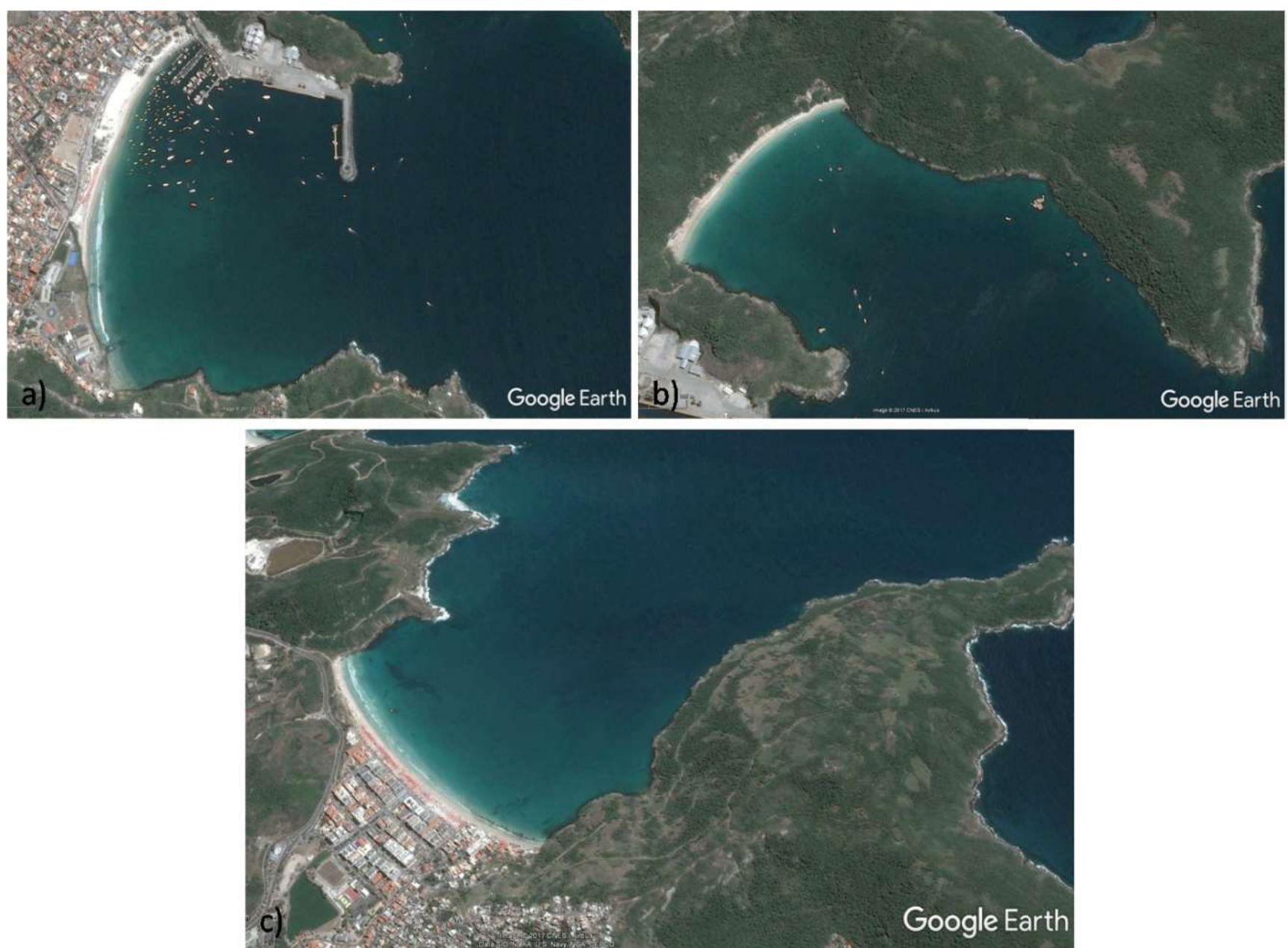

Figura 2 - Imagens de Satélite das Enseadas de Arraial do Cabo-RJ. a) Enseada dos Anjos; b) Enseada do Forno; e c) Enseada da Prainha. Fonte: Google Earth 
Sobre a mobilização dos depósitos arenosos das enseadas de Arraial do Cabo, entende-se que, de acordo com as oscilações recentes do nível do mar, discutidas para a área de estudo por Milne, Long e Bassett (2005), Angulo, Lessa e Souza (2006), Castro et al. (2012), Castro et al. (2014) e Angulo et al. (2016), o mesmo atingiu o paleonível aproximado de $3,0 \pm 1,0 \mathrm{~m}$ acima do atual entre 4,1 e 3,5 mil anos calibrados antes do presente. Esse nível é coerente com a altura atual das barreiras arenosas e praias emersas (desconsiderando o capeamento eólico) em questão. Desde pelo menos 4,4 mil anos calibrados antes do presente, os dados para a área de estudo indicam nível do mar em regressão, o que exerce forças na posição e distribuição do depósito sedimentar emerso e submerso das enseadas.

\section{Materiais e Métodos}

\subsection{Definições da Grade Amostral e Coleta de Sedimentos}

A primeira etapa foi a definição da grade amostral de coleta de sedimentos. O intervalo entre as amostras foi definido com foco na aplicação dos modelos de transporte de sedimentos, o qual também é suficiente para a representatividade textural da área dos depósitos nas enseadas. A distância aproximada dos pontos de coleta nas enseadas foi de 150m na Enseada da Prainha, 200m na Enseada do Forno e 150m na Enseada dos Anjos. A grade amostral foi definida com o programa Google Earth Pro na porção submersa das enseadas (Figura 1), totalizando 96 amostras. A segunda etapa visou a captura dos sedimentos de fundo, com o auxílio de embarcação pequena do tipo lancha, equipamentos de posicionamento global, cordas e draga de fundo do tipo Van Veen.

\subsection{Amostras em Laboratório}

Em laboratório, a primeira etapa foi a retirada do conteúdo de sais dissolvidos através de sucessivas lavagens com $800 \mathrm{ml}$ de água destilada. Essa etapa deve ser cuidadosa para não haver perda das frações mais finas da amostra. Utilizou-se uma solução a 10\% de peróxido de hidrogênio para eliminação da matéria orgânica, o que também foi útil para a desagregação de partículas e retirada dos sais. Em seguida, a amostra foi disposta em estufa a $100^{\circ} \mathrm{C}$ para a secagem por evaporação. $\mathrm{O}$ tempo dependeu da quantidade de água remanescente, mas normalmente em 48 horas as amostras foram retiradas da estufa.

\subsubsection{Método do Peneiramento a Seco}

Para o peneiramento a seco partiu-se das duas etapas descritas no item anterior e, em seguida, foi feito o quarteamento utilizando um quarteador do tipo Jones. O objetivo foi selecionar uma subamostra entre 40 e 60 gramas que pudesse representar, proporcionalmente, as frações granulométricas da amostra como um todo. Após o quarteamento, foi determinado o peso inicial da amostra.

Em seguida, montou-se o jogo de peneiras em intervalos de $0,5 \mathrm{em} 0,5 \Phi$ e intervalos finais representados por peneiras de 0,25 em $0,25 \Phi$ para refinamento da "cauda" da curva de assimetria positiva (BULHÕES; ESTRADA, 2011). As amostras, então, foram submetidas a agitadores mecânicos durante 16 minutos, com uma velocidade de vibração constante. Após a agitação das peneiras, foi pesada a fração retida em cada uma delas, o que então foi processado estatisticamente utilizando o programa Gradistat v.7 (BLOTT; PYE, 2001).

\subsubsection{Método Ótico}

A análise conhecida como LD (Laser Diffraction) é o método utilizado pelo equipamento granulômetro laser que se baseia na resposta da difração de raios laser na determinação do tamanho das partículas. Cada partícula vai ter seu padrão de dispersão próprio. $\mathrm{O}$ procedimento iniciou pelo preparo da amostra, retirada dos sais através de sucessivas lavagens e da matéria orgânica através de solução de $10 \mathrm{ml}$ de peróxido de hidrogênio. Para o aparelho, foram utilizados entre 5 e 10 gramas da amostra que, por especificações técnicas, não devem ter diâmetro maior que $1,0 \mathrm{~mm}$. As análises foram executadas utilizando configurações padronizadas, o que inclui determinação do nível de obscuração, utilização de ultrassom e determinação da quantidade de leituras. Os resultados finais saíram para cem intervalos de classe que, posteriormente, foram utilizados para cálculos dos parâmetros estatísticos também no programa Gradistat v.7 (BLOTT; PYE, 2001).

\subsubsection{Métodos de Interpolação e Elaboração de Mapas de Distribuição de Sedimentos}

Para Bulhões e Drumond (2012), o método eficiente para a interpolação de sedimentos arenosos de fundo é o kriging. De acordo com Landim (2003), o 
kriging é utilizado na previsão do valor de uma variável regionalizada em um locais não amostrados dentro do plano geométrico. É um método de interpolação exato que considera todos os valores observados. Pode ser usado ainda para o cálculo da média de uma variável regionalizada para um volume ou área maior que o plano geométrico (efeito extrapolação). É utilizando também para estimativas de deriva, similar às superfícies de tendência. $\mathrm{O}$ kriging usa informações do semivariograma para encontrar os pesos ótimos a serem associados às amostras que irão estimar um ponto, um painel ou um bloco (LANDIM, 2003; 2006). Como o semivariograma é função da distância entre as amostras, determinam-se pesos diferentes de acordo com o arranjo espacial definido pela malha amostral. Ainda segundo Landim (2003), com esse método, torna-se viável a melhor estimativa possível para locais não amostrados, pela minimização da variância do erro.

Os mapas de distribuição dos dados interpolados pelo método kriging foram elaborados com o programa ArcMap 10.1 e, seguindo recomendações da UNESCO (1986), utilizaram-se informações sobre a linha de costa e profundidades a partir da Carta Náutica CN 1503 Enseadas do Cabo Frio, disponibilizada pela Diretoria de Hidrografia e Navegação da Marinha do Brasil.

\subsection{Parametrização Estatística e Tendências de Transporte de Sedimentos}

A escala de grade proposta por Wentworth (1922) é a utilizada neste trabalho e subdivide o conjunto de dados aqui encontrado em: areia muito grossa, areia grossa, areia fina, areia muito fina, silte grosso e silte médio. As subdivisões dadas em milímetros pela escala de Wentworth (1922) podem ser também utilizadas na unidade phi $(\Phi)$, conforme proposta por Krumbein (1934), e, pelas suas vantagens, foi aqui selecionada. Adicionalmente, para os parâmetros de dispersão, foram adotados os limites terminológicos propostos por Folk e Ward (1957), conforme a Tabela I.

Tabela I: Limites terminológicos propostos por Folk e Ward, 1957

\begin{tabular}{c|c|c|c|c|c}
\hline \multicolumn{2}{c|}{ Limites de Desvio Padrão } & \multicolumn{2}{c|}{ Limites de Assimetria } & \multicolumn{2}{c}{ Limites de Curtose } \\
\hline $\begin{array}{c}\text { Muito Bem } \\
\text { Selecionado }\end{array}$ & 0,35 & Muito negativa & -1 & $\begin{array}{c}\text { Muito } \\
\text { Platicúrtica }\end{array}$ & 0,67 \\
\hline Bem Selecionado & 0,5 & Negativa & $-0,3$ & Platicúrtica & 0,9 \\
\hline $\begin{array}{c}\text { Moderadamente } \\
\text { Selecionado }\end{array}$ & 1 & Simétrica & $-0,1$ & Mesocúrtica & 1,11 \\
\hline Mal Selecionado & 2 & Positivo & 0,1 & Leptocúrtica & 1,5 \\
\hline $\begin{array}{c}\text { Muito Mal } \\
\text { Selecionado }\end{array}$ & 4 & Muito Positivo & $>0,3$ & $\begin{array}{c}\text { Muito } \\
\text { Leptocúrtica }\end{array}$ & 3 \\
\hline
\end{tabular}

O modelo de transporte de sedimentos utilizado foi o GSTA através da aplicação proposta por Poizot e Méar (2010) denominada de GISEDTREND. Trata-se de um complemento para o sistema de informação geográfica QGIS. Para tal aplicação, foram usados como dados de entrada os resultados dos parâmetros Média, Desvio Padrão e Assimetria, assim como a distância entre as amostras e os padrões de transporte selecionados para a modelagem foram FB-, $\mathrm{CB}+$, FB+ e CB-.

\section{Resultados e Discussão}

A distribuição do parâmetro média granulométrica (Figura 3) indica que, nas três enseadas, há o predomínio de areias finas $(41,6 \%)$, sobretudo nas proximidades da praia emersa, informação que concorda com o apresentado por Silva (2009), que é o padrão regional para a área no entorno da ilha do Cabo Frio. As areias médias (17,7\%) são também representativas, indicando oscilações de maior energia. Areias grossas (14,6\%) e muito grossas $(8,3 \%)$ ocorrem em menor proporção, associadas às proximidades dos promontórios rochosos. Trata-se de sedimentos com maior teor de biodetritos, resultantes do ataque das ondas sobre as comunidades bioincrustradas nos costões rochosos, também encontrados em resultados quantificados de Tavares, Bulhões e Estrada (2010) e Estrada e Bulhões (2010) para enseadas próximas. Já os sedimentos mais finos, como a areia muito fina $(5,2 \%)$ e os siltes $(6,2 \%)$, ocorrem associados à porção externa das enseadas, sugerindo limites de sedimentação na antepraia. 


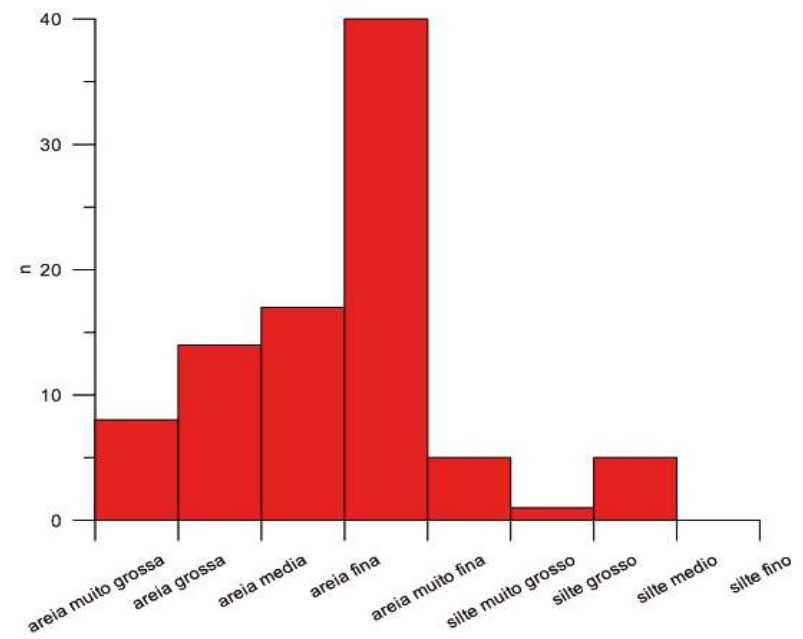

Figura 3 - Histograma representativo do universo amostral.
Essa sedimentação de areias muito finas e finas, na enseada da Prainha, e que ocorre no entorno das isóbatas de -20 metros (Figura 4), deve ser relacionada ao observado por Pereira et al. (2007) como uma sedimentação neotérica que ocorre em profundidades entre $10 \mathrm{~m}$ e $30 \mathrm{~m}$ no arco praial adjacente. Além disso, para arcos praiais e enseadas ainda ao norte da área de estudo, foram verificados resultados semelhantes em trabalhos de Tavares, Bulhões e Estrada (2010), Muehe et al. (2011), Bulhões et al. (2014) e Bulhões e Fernandez (2016). Esse padrão de sedimentação é resultante de um transporte litorâneo residual de sedimentos neotéricos, de origem fluvial, sentido norte-sul.

Parâmetro Média.

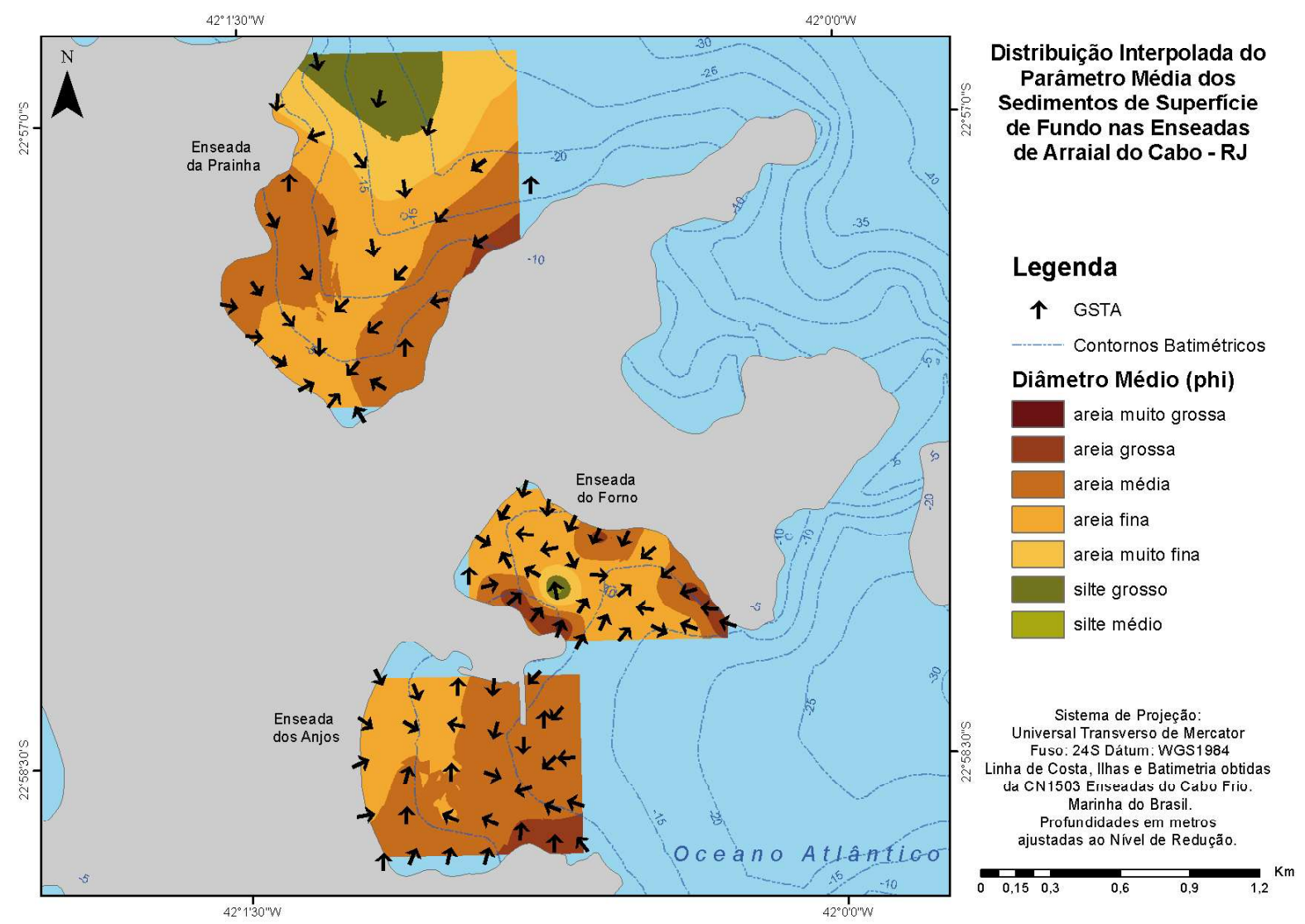

Figura 4 - Distribuição interpolada do diâmetro médio granulométrico com sobreposição dos vetores de transporte de sedimentos.

A Figura 4 apresenta ainda a sobreposição dos vetores de transporte de sedimentos resultante da aplicação do modelo GSTA de Poizot e Méar (2010). Esses resultados apontam para a enseada da Prainha transporte em direção à praia na porção central e, junto à praia emersa, um transporte no sentido sudeste, para a direita de um observador olhando para o mar. Nessa enseada, o melhor ajuste foi com o modelo CB- (46\%) seguido do $\mathrm{FB}+(28,6 \%)$. O efeito dos promontórios rochosos que limitam as enseadas indica que os sedimentos tendem a ser transportados a partir deles para a porção central nas três enseadas.

$\mathrm{Na}$ enseada da praia do Forno, os vetores indicam, a partir da isóbata de $-10 \mathrm{~m}$, que o transporte segue em 
direção à praia emersa e, na praia, há ligeira indicação de transporte em direção ao sul, também para a direita de um observador olhando para o mar. A partir da isóbata dos $-10 \mathrm{~m}$ para maiores profundidades, sugere-se que $\mathrm{o}$ transporte não está mais associado ao abastecimento da praia, provavelmente em função de o promontório no limite sudoeste deixar de exercer influência. Nesta enseada, o modelo FB- respondeu a $81 \%$ para o melhor ajuste dos vetores.

$\mathrm{Na}$ enseada da praia dos Anjos, os vetores de transporte (Figura 4) indicam majoritariamente transporte em direção à praia desde a isóbata de $-10 \mathrm{~m}$. Há uma ligeira tendência de inflexão do transporte em direção à porção norte da enseada, ou seja, para a esquerda de um observador olhando para o mar. Esse fato já havia sido identificado por Savi (2007), que, a partir de um modelo hidrodinâmico e perfis de praia, evidenciou a participação do efeito sombra do "quebramar" na energia direcionada para a enseada e a tendência desta de se ajustar, transportando, residualmente, sedimentos em direção ao norte. Ainda na enseada da praia dos Anjos, nas proximidades da praia emersa, os vetores indicam transporte transversal em direção à antepraia, e até a isóbata de -5m o transporte tende para o norte, o que novamente corrobora o encontrado por Savi (2007). O melhor ajuste para esta enseada ocorreu com o modelo $\mathrm{FB}+(42 \%)$ seguido do $\mathrm{CB}+(30 \%)$.

A interpolação do parâmetro desvio padrão, cuja leitura permite identificar o grau de selecionamento das amostras, observado na Figura 5, indica melhor grau de selecionamento em direção às menores profundidades, sobretudo na enseada da Prainha. Tratase do selecionamento produzido por ação de ondas, amplamente citado na literatura (ex. KOMAR, 1976; DEAN; DALRYMPLE, 2002) e também encontrado por Bulhões e Fernandes (2016) para as enseadas do Cabo Búzios, ao norte. Há também uma piora no grau de selecionamento das amostras em direção à antepraia e na direção dos promontórios rochosos. $\mathrm{Na}$ antepraia, entre as profundidades de $5 \mathrm{~m}$ e $10 \mathrm{~m}$, a piora no grau de selecionamento possivelmente está associada ao padrão de movimentação anômalo induzido por correntes de fundo, conforme identificado por Ingle $\operatorname{Jr}$ (1966). Junto aos promontórios rochosos, os piores resultados do grau de selecionamento está associado à ocorrência de biodetritos.

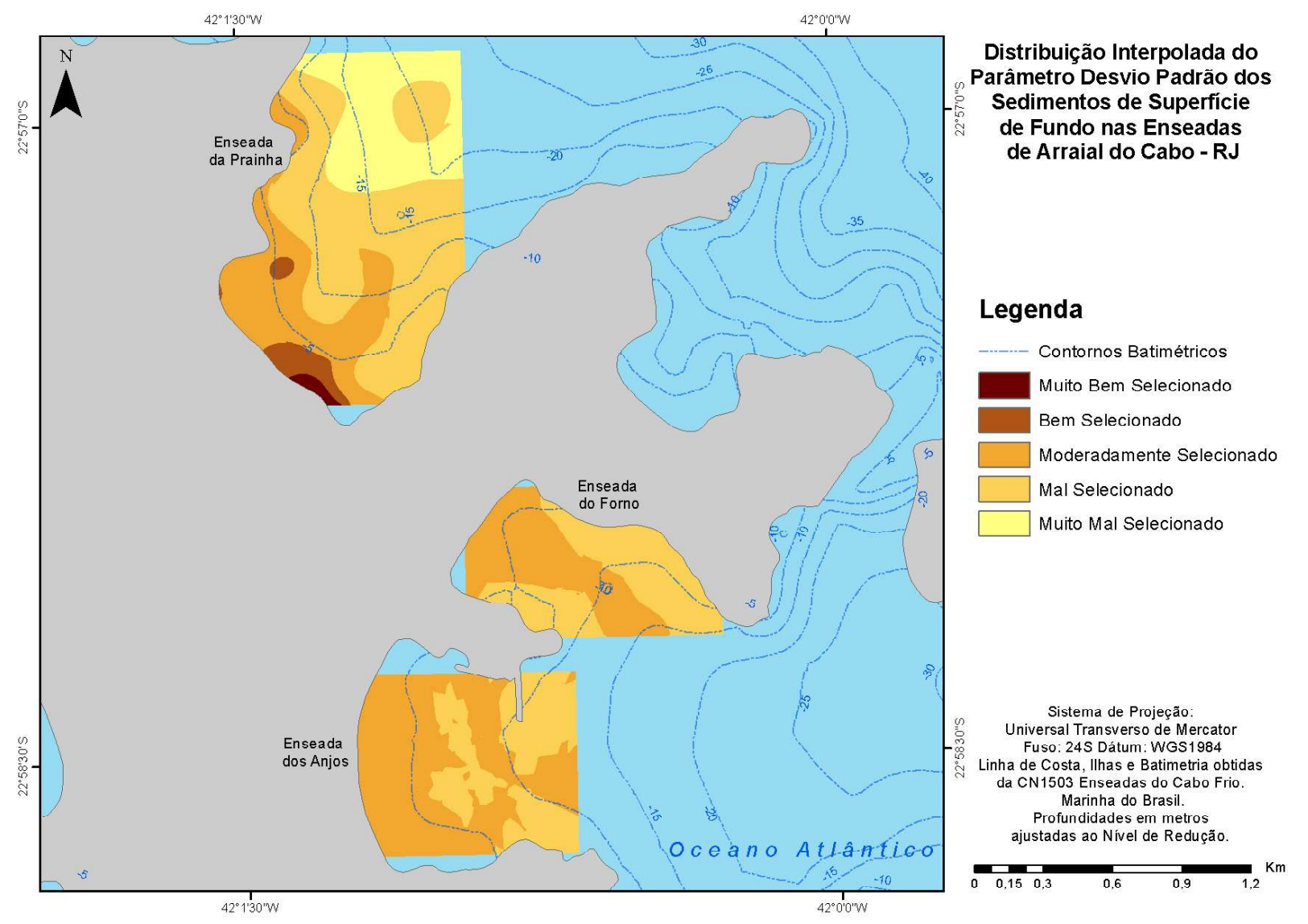

Figura 5 - Distribuição interpolada do desvio padrão granulométrico indicando o grau de selecionamento. 
O gráfico da Figura 6 relaciona as profundidades com o grau de selecionamento das amostras e confirma esse resultado, indicando que a ação das ondas no selecionamento dos grãos é realmente melhor em direção à praia emersa. Já em direção ao fundo, os padrões de selecionamento pioram.

Outra ligeira tendência identificada, conforme o gráfico da Figura 7, ao relacionar o diâmetro mediano das amostras com o grau de selecionamento, foi o melhor selecionamento obtido dentre as areias finas e muito finas, o que concorda com o modelo de Inman (1949), segundo o qual apenas areias finas recaem

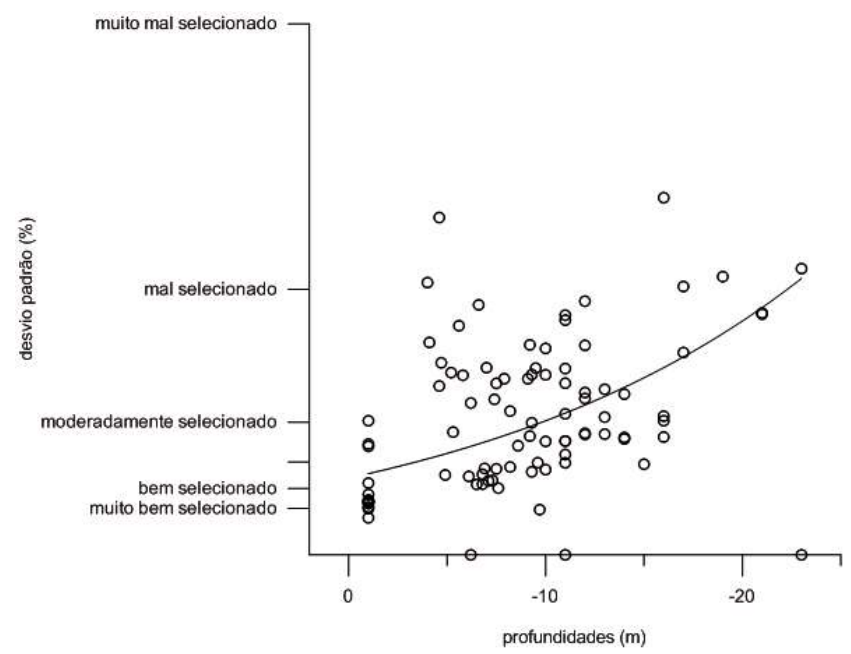

Figura 6 - Gráfico Profundidades vs Desvio Padrão.

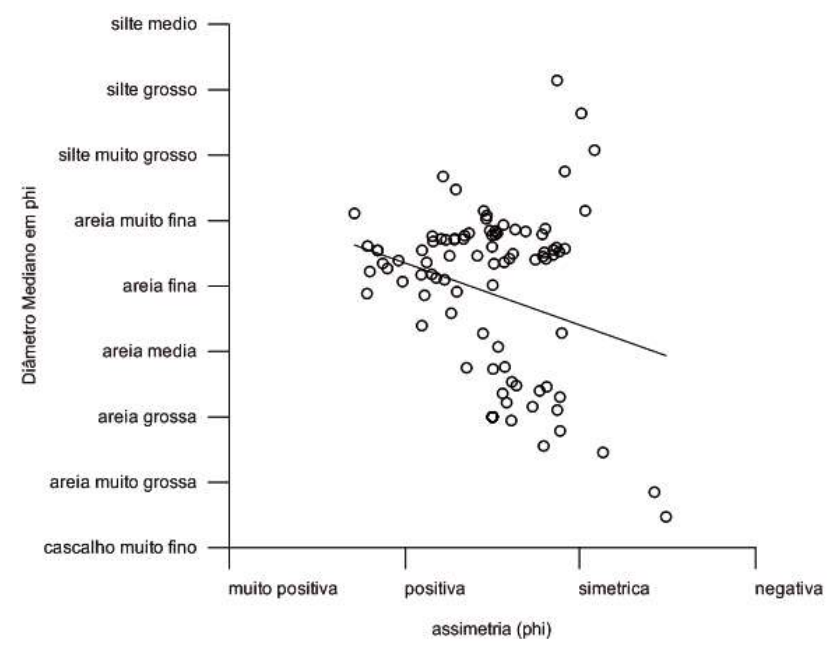

Figura 8 - Gráfico Assimetria vs Diâmetro Mediano

Duane (1964) relaciona os valores de distribuição do parâmetro assimetria positiva a áreas onde predominam mecanismos de deposição de sedimentos e os valores de assimetria negativa aos mecanismos de erosão. A figura 9 na classe de bem selecionadas. Por sua vez, essas areias finas correspondem majoritariamente às frações representativas de menores profundidades.

O resultado do parâmetro assimetria pode ser observado no gráfico da Figura 8 em sua relação com a distribuição dos diâmetros medianos das amostras. Esses resultados concordam com o padrão observado por autores desde Inman (1949), em que grãos grossos tendem à assimetria negativa e grãos finos tendem à assimetria positiva, algo também observado por Folk e Ward (1957). Em relação à caracterização do depositário, esse parâmetro teve pouco a contribuir.

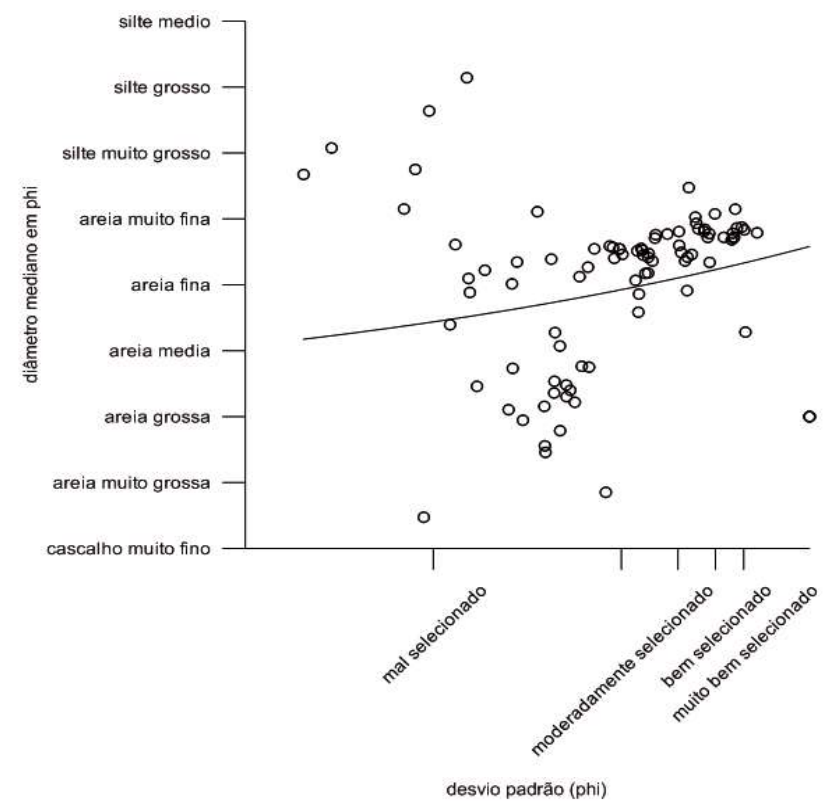

Figura 7 - Gráfico Desvio Padrão vs Diâmetro Mediano

apresenta a distribuição do parâmetro assimetria para as enseadas da área de estudo, e os valores de assimetria são positivos ou muito positivos na maior parte das enseadas, com exceção da Enseada dos Anjos, onde os resultados indicam simetria. Pontualmente ocorrem duas posições com assimetria negativa, o que, de acordo com o modelo do autor supracitado, indicaria áreas onde ocorre remoção de frações. De uma forma geral, ainda seguindo o modelo de Duane (1964), há o predomínio geral de mecanismos de deposição nas enseadas de Arraial do Cabo.

O parâmetro curtose usualmente indica tendências deposicionais quando platicúrtica, pois infere uma mistura de populações diferentes e, quando leptocúrtica, pode inferir tendências de transporte ao indicar a remoção de algumas frações por meio de correntes de fundo ou outros forçantes (PONÇANO; GIMENEZ; 
FULFARO, 1976; MACHADO, 2007). O gráfico da Figura 10 indica ligeira tendência de serem leptocúrticas as amostras de diâmetro mediano mais fino, sugerindo remoção ou a não deposição de frações médias e grossas nessas posições. Há então a tendência nestas enseadas de as amostras que apresentam curtose leptocúrtica terem melhor selecionamento (Figura 11).

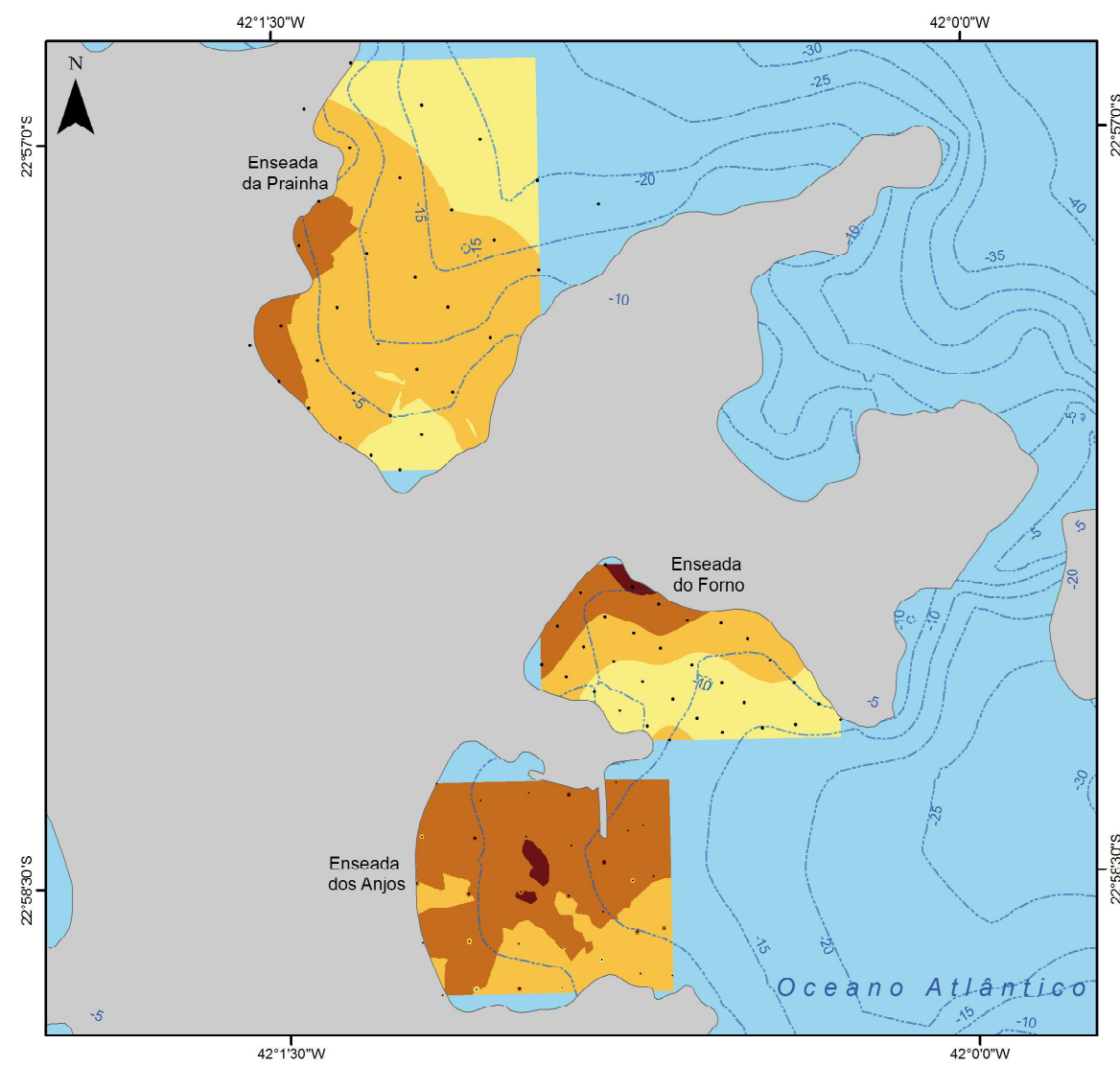

Distribuição Interpolada do

Parâmetro Assimetria dos

Sedimentos de Superfície

de Fundo nas Enseadas

de Arraial do Cabo - RJ

Legenda

Negativa

Simétrica

Positivo

Muito Positivo

Sistema de Projeção

Universal Transverso de Mercator ha de Costa, Ilhas e Batimetria obtida da CN1503 Enseadas do Cabo Frio.

Marinha do Brasil.

Profundidades em metros

ajustadas ao Nível de Redução.

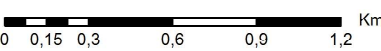

Figura 9. Distribuição interpolada do parâmetro Assimetria.

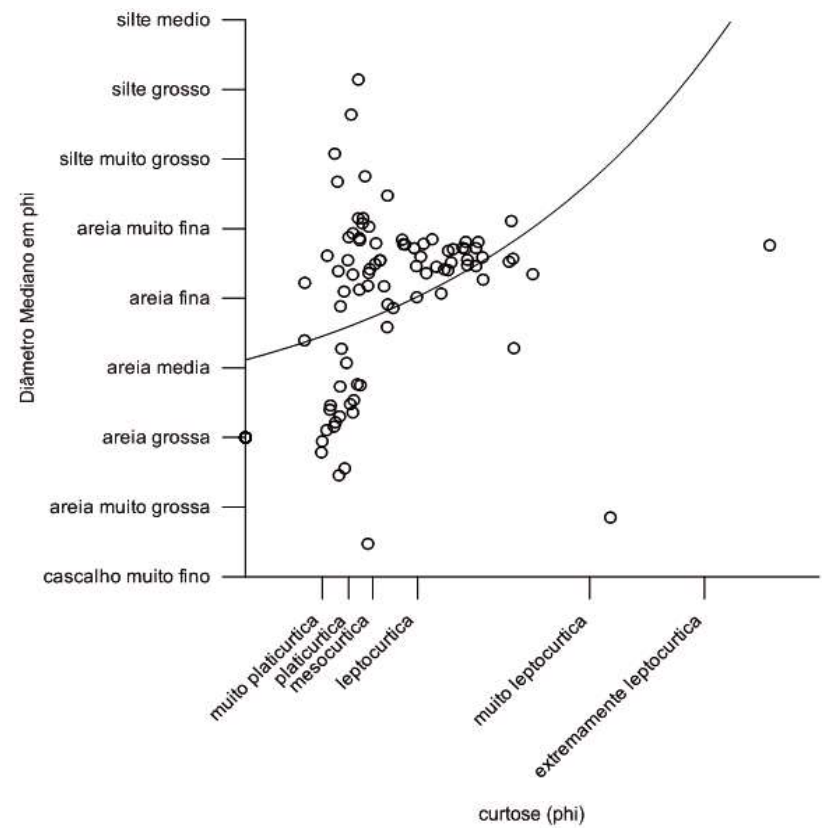

Figura 10 - Curtose vs Diâmetro Mediano.

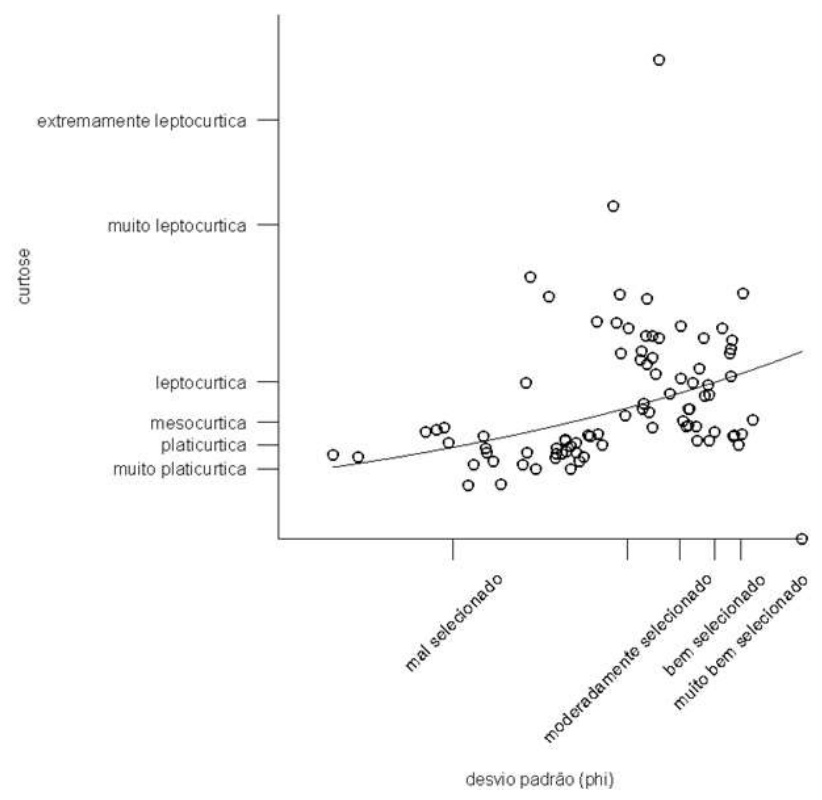

Figura 11 - Desvio Padrão vs Curtose. 
Adicionalmente, o padrão de distribuição desse parâmetro (Figura 12) indica para a enseada da praia dos Anjos tendências leptocúrticas, o que sugere remoção de frações na porção sudeste da enseada e tendências platicúrticas nas posições junto à praia, indicando mistura de frações granulométricas em áreas de deposição, sobretudo na porção norte. Esse resultado é novamente concordante com o sugerido por Savi (2007), mesmo que o autor não tenha analisado parâmetros granulométricos, e ainda dá subsídios para entender o desequilíbrio sedimentar que promoveu processo erosivo na porção sul da praia dos Anjos. Para a Enseada do Forno, a distribuição do parâmetro curtose indica remoção de frações (quando leptocúrtica) nas posições mais próximas à praia emersa, o que concorda com os vetores indicados na Figura 4. Esse padrão é inverso ao da praia dos Anjos. Por fim, as tendências mesocúrticas observadas nas outras porções das enseadas em análise não permitem inferências.

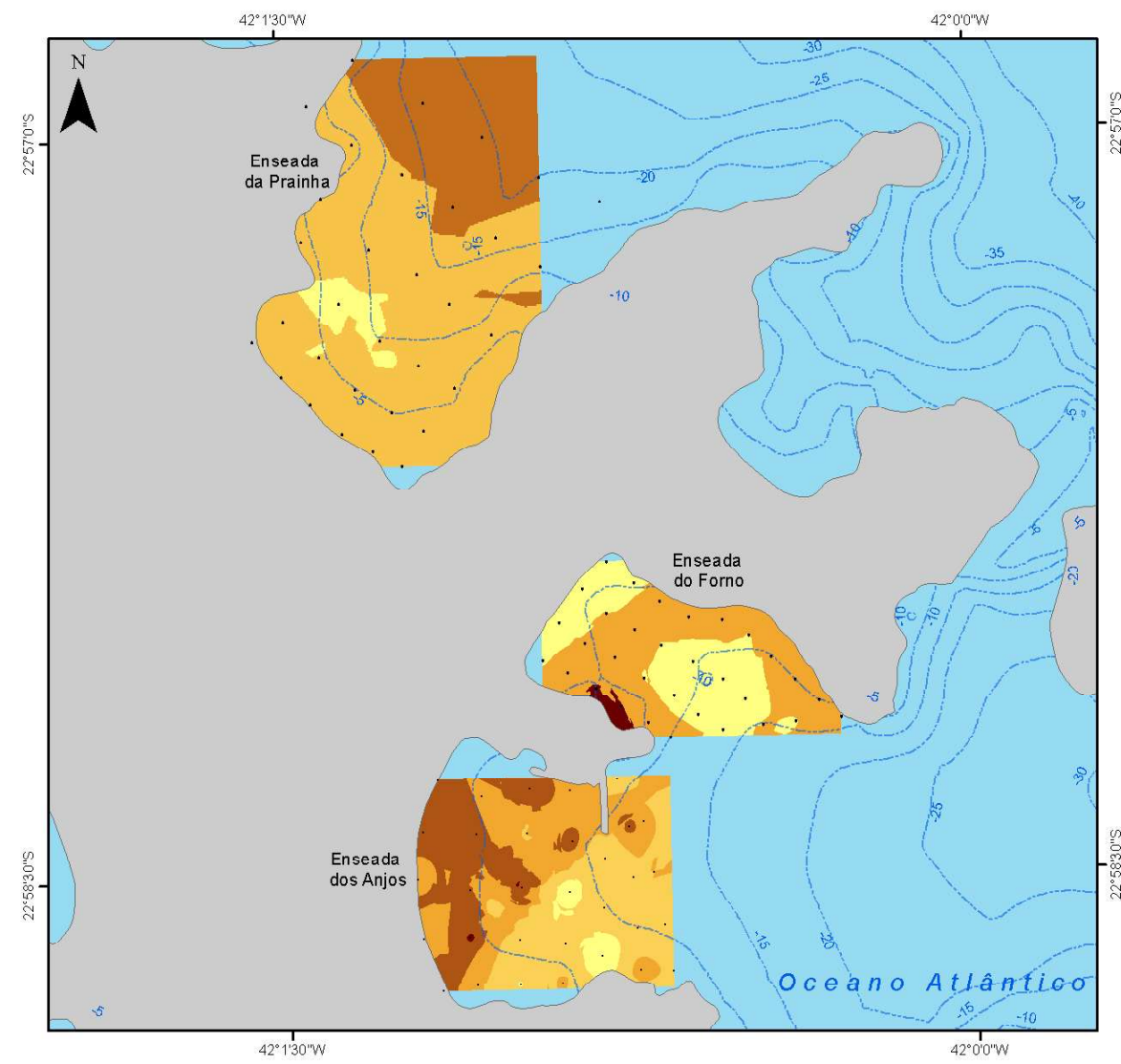

\section{Distribuição Interpolada do Parâmetro Curtose dos Sedimentos de Superfície de Fundo mais Vetores de Transporte nas Enseadas de Arraial do Cabo - RJ}

\section{Legenda}

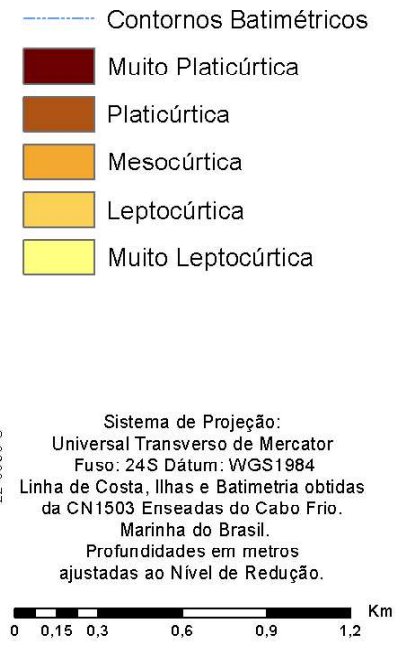

Figura 12 - Distribuição interpolada do parâmetro Curtose. 


\section{Conclusões}

Praias de enseada em ambientes arenosos e de micromaré, usualmente semiabrigados, são laboratórios que permitem esse tipo de problematização. Além disso, os acessos, as dimensões e distâncias, a facilidade na instrumentação e levantamento de dados e o maior controle sobre algumas variáveis (ex. posição) permitem resultados confiáveis e de melhor resolução espacial. Nesse sentido, para as três enseadas de Arraial do Cabo, são nítidas as variações entre materiais arenosos mais finos e mais grossos. Não foram encontradas áreas de sedimentação com frações argilosas, o que exclui a hipótese de praias de enseada de baixa energia. No geral, as praias de enseada na área de estudo são compostas por areias finas e areias médias, fruto de uma sedimentação arenosa palimpsesta na antepraia, que é a responsável por abastecer a praia emersa. Adicionalmente, pequenos depósitos de areias grossas e muito grossas mal selecionadas ocorrem associados às margens de costões rochosos, relacionáveis à presença de teores elevados de biodetritos. Por fim, há a indicação para a porção norte da área de estudo de uma sedimentação neotérica siltosa, não associada ao ambiente de praia, concordante com o observado em enseadas ao norte da área de estudo (MUEHE et al., 2011; BULHÕES et al., 2014; BULHÕES; FERNANDEZ, 2016), sendo uma área de sedimentação neotérica da plataforma continental interna em profundidades entre $10 \mathrm{~m}$ e $30 \mathrm{~m}$.

Já o modelo de transporte de sedimentos considerou majoritariamente a ocorrência do padrão FB (sedimentos mais finos e mais bem selecionados na direção do transporte) em $65 \%$ com assimetria variando entre positiva (35\%) e negativa (30\%). Esses padrões de transporte seguem o indicado pela literatura desde McLaren (1981) como o melhor ajuste para depósitos majoritariamente compostos por sedimentos finos (POIZOT; MÉAR, 2010). Especificamente nas enseadas em análise, aparentemente os melhores resultados foram encontrados para a Enseada da Prainha, possivelmente devido a sua exposição para as ondas de NNE e ventos de NE, que são modais para esta parte do litoral. Nas enseadas do Forno e dos Anjos, os padrões de transporte encontrados são aparentemente mais complexos, possivelmente por ação e combinação de agentes deposicionais e de transporte não avaliados neste estudo (ex. bimodalidade do clima de ondas, marés, presença de estruturas artificiais). No entanto, há clara indicação, para a Enseada do Forno, de transporte orientado para a porção central da enseada e um afinamento do diâmetro médio em direção à praia emersa associado a uma melhora no selecionamento dos grãos por ação de ondas. Na Enseada dos Anjos, observa-se que os vetores de transporte favorecem a saída de materiais da porção sul do arco praial, o que pode ser diagnóstico do processo erosivo ali estabelecido. Fica então a indicação de que análises e testes de modelos não hidrodinâmicos de transporte de sedimentos com base na distribuição dos parâmetros estatísticos granulométricos são resultados que geram informações úteis, dentre outras coisas, para diagnósticos de erosão costeira, para a temática ambiental, para a determinação de processos governantes da agitação oceânica em praias, e suas resultantes morfossedimentares, e para a calibração e validação de modelos com bases hidrodinâmicas, sendo esta a perspectiva futura da pesquisa.

\section{Referências Bibliográficas}

ANDRIOTTI, J. L. S. Fundamentos de estatística e geoestatística. $1^{a}$ Edição. São Leopoldo: Editora Unisinos, 2003, 165p.

ANGULO, R. J.; LESSA, G. C.; SOUZA, M. C. A critical review of mid to late Holocene sea-level fluctuations on the eastern Brazilian coastline. Quaternary Science Reviews, v. 25, n. 5, p. 486-506, 2006.

ANGULO, R. J.; GIANNINI, P. C.; SOUZA, M. C. D.; LESSA, G. C. Holocene paleo-sea level changes along the coast of Rio de Janeiro, southern Brazil: Comment on Castro et al. (2014). Anais da Academia Brasileira de Ciências, v. 88, n. 4, p. $2105-$ 2111, 2016.

BARBIÉRE, E. B. Cabo Frio e Iguaba Grande, dois microclimas distintos a um curto intervalo espacial. In: LACERDA, L. D.; ARAUJO, D. S. D.; CERQUEIRA, R.; TURCQ, B. (Org.) Restingas: origem, estrutura, processos. Anais do Simpósio sobre Restingas Brasileiras. Niterói: CEUFF, 1984. p. 3-12, 1984.

BLOTT, S. J.; PYE, K. Gradistat: A grain size distribution and statistics package for the analysis of unconsolidated sediments. Earth Surface Processes and Landforms, v. 26, n. 11, p. 12371248, 2001.

BULHÕES, E.; ESTRADA, A. F. D. Distribuição e transporte de sedimentos costeiros em ambiente de baixa energia. Enseada da Ferradura, Armação dos Búzios, Rio de Janeiro, Brasil. Revista Gravel, v. 9, n. 1, p. 41-56, 2011.

BULHÕES, E.; DRUMOND, M. K. Análises e testes de métodos 
de interpolação para dados batimétricos e granulométricos: estudo de caso em Armação dos Búzios, Rio de Janeiro, Brasil. Cadernos de Estudos Geoambientais, v. 3, n. 1, p. 5-31, 2012.

BULHÕES, E.; FERNANDEZ, G. B.; OLIVEIRA FILHO, S. R.; PEREIRA, T. G.; ROCHA, T. B. Impactos costeiros induzidos por ondas de tempestade entre o Cabo Frio e o Cabo Búzios, Rio de Janeiro, Brasil. Quaternary and Environmental Geosciences, v. 5, n. 1, p. 154-165, 2014.

BULHÕES, E.; FERNANDEZ, G. B. Aspectos morfodinâmicos em praias de enseada: Estudo de caso em Armação dos Búzios, RJ. Revista Brasileira de Geomorfologia, v. 17, n. 2, p. 253271, 2016.

BULHÕES, E.; FERNANDEZ, G. B.; OLIVEIRA FILHO, S. R.; PEREIRA, T. G. Coastal impacts induced by storm waves between Cape Frio and Cape Búzios, Rio de Janeiro, Brazil. Journal of Coastal Research, v. SI75, p. 1047-1051, 2016.

BRONNIMANN, P.; MOURA, J. A.; DIAS-BRITO, D. Estudos ecológicos na Baía de Sepetiba, Rio de Janeiro, Brasil: Foraminíferos. In: Congresso Latino-Americano de Paleontologia, 2, 1981, Porto Alegre. Anais. Porto Alegre, p. 862-875.

CAMPOS, R. M. Análise dos extremos de onda no Rio de Janeiro associados a ciclones extratropicais no Atlântico Sul. Dissertação (Mestrado em Engenharia Oceânica). COPPE/UFRJ, Rio de Janeiro, 2009. 269p.

CASTro, J. W. A.; SUGUIO, K.; DA CUNHA, A. M.; GUEDES, E.; SOUZA TÂMEGA, F. T.; RODRIGUEZ, R. Rochas de praia (beachrocks) da Ilha do Cabo Frio, Arraial do Cabo: registro geológico ímpar da transição pleistocenoholoceno no Estado do Rio de Janeiro. Anuário do Instituto de Geociências, v. 35, n. 1, p. 236-241, 2012.

CASTRO, J. W. A.; SUGUIO, K.; SEOANE, J.; CUNHA, A. M.; DIAS, F. F. Sea-level fluctuations and coastal evolution in the state of Rio de Janeiro, Southeastern Brazil. Anais da Academia Brasileira de Ciências, v. 86, n. 2, p. 671-683, 2014.

DAVIS JR, R. A. Coastal sedimentary environments. New York: Springer Verlag, 1985.

DIAS, J. A. A análise sedimentar e o conhecimento dos sistemas marinhos. Faro: Universidade do Algarve, 2004. E-Book.

DEAN, R.G. Beach nourishment: theory and practice. Singapore: World Scientific Publishing, 2002. 399p.

DUANE, D. B. Significance of skewness in recent sediments, West Pamlico Sound, North Carolina. Journal of Sedimentary Petrology, v.34, n.4, p. 864-874. 1964
EMERY, K. O.; KUHN, G. G. Sea Cliffs: Their Processes, Profiles and Classification. Geological Society of America Bulletin, v. 93, n. 7, p. 644-654, 1982.

ESTRADA, A. F. D.; BULHÕES, E. Aspectos erosivos na enseada da Praia Brava, Armação dos Búzios, Rio de Janeiro. In: Simpósio Nacional de Geomorfologia, VIII, 2010. Recife. Anais. UGB, 2010.

FOLK, R. L.; WARD, W. C. Brazos river bar: A study in the significance of grain size parameters. Journal of Sedimentary Petrology. v. 27, n. 1, p. 3-26, 1957.

GAO, S; COLLINS, M.A Critique of the "McLaren method" for defining sediment transport paths-discussion. Journal of Sedimentary Petrology, v. 61, n.1, 1991.

GAO, S.; COLLINS, M. Net sediment transport patterns for defining sediment transport pathways in marine environments. Sedimentary Geology. v. 81, n. 1-2, p. 47-60, 1992.

GAO, S.; COLLINS, M. Analysis of grain size trends for defining sediment transport pathways in marine environments. Journal of Coastal Research. v. 10, n.1, p. 70-78, 1994.

GAO, S.A Fortran program for grain-size trend analysis to define net sediment transport pathways. Computers \& Geosciences, v. 22, n.4, p. 449-452, 1996.

INGLE, J. The movement of beach sand. An analysis using fluorescent grains. Developments in Sedimentology 5. Amsterdam: Elsevier Publishing Company, 1966.

INMAN, D. L. Sorting of sediments in the light of fluid mechanics. Journal of Sedimentary Petrology, v. 19, n. 2, p. 51-70, 1949.

INMAN, D. L.; NORDSTROM, K.F. On the tectonic and morphologic classification of coasts. Journal of Geology, v. 79, n.1, p. 1-21, 1971.

KLEIN. A. H. F. Morphodynamics of headland bay beaches: examples from the coast of Santa Catarina state, Brazil. Tese (PhD Ciências do Mar e do Ambiente) Universidade do Algarve, Faro, 2004.

KOMAR, P. D. Beach processes and sedimentation. New Jersey: Prentice Hall, 1976.

KRUMBEIN, W. C. Size frequency distributions of sediments. Journal of Sedimentary Research, v. 4, n. 2, p. $65-$ 77, 1934.

KRUMBEIN, W. C.; PETTIJOHN, F. J. Manual of sedimentary petrography. New York: Appleton-Century Company Inc., 1938. $550 \mathrm{p}$. 
LANDIM, P. M. B. Análise estatística de dados geológicos. 2a. Edição. São Paulo: Editora da UNESP, 2003. 253p.

LANDIM, P. M. B. Sobre geoestatística e mapas. Terrae Didática, v. 2, n. 1, p. 13-33, 2006.

LEATHERMAN, S. P. Barrier island handbook. 3rd Edition. College Park: University of Maryland, 1988.

LE ROUX, J. P. An alternative approach to the identification of net sediment transport paths based on grain-size trends. Sedimentary Geology, v. 94, n. 1-2, p. 97-107, 1994.

LE ROUX, J. P.; ROJAS, E. M. Sediment transport patterns determined from grain size parameters: Overview and state of the art. Sedimentary Geology, v. 202, n. 3, p. 473-488, 2007.

MACHADO, G. M. V. Análise morfossedimentar da praia, antepraia e plataforma continental interna da linha de costa do Parque Nacional de Jurubatiba, RJ. Dissertação (Mestrado em Geografia), PPGG/UFRJ, Rio de Janeiro, 2007.

MAHIQUES, M. M.; FURTADO, V. V. Utilização da análise dos componentes principais na caracterização dos sedimentos de superfície de fundo da Baía da Ilha Grande (RJ). Boletim do Instituto Oceanográfico, v. 37, n. 1, p. 1-19, 1989.

MAHIQUES, M. M.; TESSLER, M. G.; CIOTTI, A. M.; SILVEIRA, I. C. A.; SOUSA, S.H.M.; FIGUEIRA, R. C. L.; TASSINARI, C. C. G.; FURTADO, V. V.; PASSOS, R. F. Hydrodynamically driven patterns of recent sedimentation in the shelf and upper slope off southeast Brazil. Continental Shelf Research. v. 24, n. 15, p.1685-1697, 2004.

MASSELING, G.; HUGHES, M.G. Introduction to coastal processes \& geomorphology. 1st Edition. New York: Oxford University Press Inc., 2003.

McLAREN, P. An interpretation of trends in grain size measures. Journal of Sedimentary Petrology. v. 51, n. 2, p. 611-624, 1981.

McLAREN, P.; BOWLES, D. The effects of sediment transport on grain-size distributions. Journal of Sedimentary Petrology. v. 55, n. 4, p. 457-470, 1985.

McLAREN, P.; HILL, S. H.; BOWLES, D. Deriving transport pathways in a sediment trend analysis (STA). Sedimentary Geology, v. 202, n. 3, p. 489-498, 2007.

McMANUS, D. Modern versus relict sediment on the continental shelf. Geological Society of America Bulletin, v. 86, p.1154-1160, 1975.

MEDEIROS, L. R. A. Meiofauna de praia arenosa da Ilha Anchieta, São Paulo: I. Fatores Físicos. Boletim do Instituto Oceanográfico, v. 40, n. 1-2, p. 27-38, 1992.
MELO, E. The sea sentinels project: watching waves in Brazil. Proceedings of VII Symposium Coastal and Ocean Management. Coastal Zone 93. ASCE. 8. p. 505-517, 1993.

MILNE, G. A.; LONG, A. J.; BASSETT, S. E. Modelling holocene relative sea-level observations from the Caribbean and South America. Quaternary Science Reviews, v. 24, n. 10, p. 1183-1202, 2005.

MIZUSAKI, A. M. P.; THOMAZ-FILHO, A. O magmatismo pós-paleozóico no Brasil. In: NETO, V. M.; BARTORELLI, A.; CARNEIRO, J. C.; BRITO-NEVES, B. B. (Org.) Geologia do Continente Sul-Americano. Evolução da Obra de Fernando Flávio Marques de Almeida. São Paulo: Editora Beca, 2004, p. 281-292.

MORTON, R. A.; GIBEAUT, J. C.; PAINE, J. G. Meso-scale transfer of sand during and after storms: implications for prediction of shoreline movement. Marine Geology. v. 126, n. 1-4, p. 161-179, 1995.

MUEHE, D. Geomorfologia costeira. In: GUERRA, A. J. T.; CUNHA, S. B. (Org.). Geomorfologia: Atualização de Bases e Conceitos. Rio de Janeiro: Editora Bertrand Brasil, 1995, p. 253-308.

MUEHE, D.; SUCHAROV, E. C. Considerações sobre o transporte de sedimentos na plataforma continental nas proximidades das Ilhas Maricás, RJ. Revista Brasileira de Geociências. v. 11, n. 4, p. 238- 246, 1981.

MUEHE, D.; BARBOSA, J. L. Resultados texturais da análise de amostras da plataforma continental interna coletadas durante a operação GEOMAR X entre a Baía de Guanabara e Ponta Negra - RJ. Geografia. v. 7, n. 13-14, p. 137-146, 1982.

MUEHE, D.; CARVALHO, V. G. Geomorfologia, cobertura sedimentar e transporte de sedimentos na plataforma continental interna entre a Ponta de Saquarema e o Cabo Frio (RJ). Boletim do Instituto Oceanográfico, v. 41, n. 1-2, p.1-1, 1993.

MUEHE, D.; NEVES, C. F. The implications of sea-level rise on the Brazilian coast: a preliminary assessment. Journal of Coastal Research, v. SI14, p. 54-78, 1995.

MUEHE, D.; DA SILVA, V. M. A. P. Morfodinâmica de praia e meiofauna: resultados preliminares. In: Reunião Especial da SBPC, III, 1996, Florianópolis. Anais. SBPC, 1996, p. 178-181.

MUEHE, D. O litoral brasileiro e sua compartimentação. In: GUERRA, A. J. T.; CUNHA, S. B. (Org.) Geomorfologia do Brasil. Cap. 7. Rio de Janeiro: Ed. Bertrand Brasil, 1998, p. 273-349.

OLIVEIRA, J. F.; MUEHE, D. Identificação de áreas de 
sedimentos compatíveis na plataforma continental interna para recuperação de praias entre as cidades de Niterói e Macaé - Rio de Janeiro, Brasil. Revista de Gestão Costeira Integrada, v.13, n. 1, p. 89-99, 2013.

PARENTE, C. E. Uma nova técnica espectral para análise direcional de ondas. Tese (Doutorado em Física) IF/UFRJ, Rio de Janeiro, 1999.

PASSEGA, R. Grain size representation by CM patterns as a geologic tool. Journal of Sedimentary Research, v. 34, n. 4, p. 830-847, 1964.

PEREIRA, T. G.; ROCHA, T. B.; SANTOS, R. A.; FERNANDEZ, G. B. Morfodinâmica entre a praia, duna e zona submarina adjacente nas proximidades do Cabo Frio, RJ. XI Congresso da Associação Brasileira dos Estudos do Quaternário. 2007.

PIANCA, C.; MAZZINI, P. L.; SIEGLE, E. Brazilian offshore wave climate based on NWW3 reanalysis. Brazilian Journal of Oceanography. v. 58, n. 1, p. 53-70, 2010.

PINHO, U. F. Caracterização dos estados de mar na bacia de campos. Dissertação de Mestrado (Engenharia Oceânica), COPPE/UFRJ, Rio de Janeiro. 2003. 123p.

PONÇANO, W. L.; GIMENEZ, A. F.; FULFARO, V. J. Sedimentação atual na Baía de Sepetiba, Estado do Rio de Janeiro: contribuição à avaliação de viabilidade geotécnica da implantação de um porto. In: Congresso Brasileiro de Geologia de Engenharia, I, 1976, Rio de Janeiro. Anais, Rio de Janeiro, 1976, p. 111-139.

POIZOT, E.; MÉAR, Y.; BISCARA, L. Sediment trend analysis through the variation of granulometric parameters: A review of theories and applications. Earth-Science Reviews, v. 86, n. 1, p. 15-41, 2008.

POIZOT, E.; MÉAR, Y. Using a GIS to enhance grain size trend analysis. Environmental Modelling \& Software, v. 25, n. 4, p. 513-525, 2010.

QUADROS, P.; CASTRO, J. W. A.; GUEDES, E.; PEREIRA, V. C. R. Distribuição Sazonal dos Sedimentos na Praia do Farol, Ilha do Cabo Frio, Arraial do Cabo, Rio de Janeiro. Revista Brasileira de Geomorfologia, v. 17, n. 2, 2016.

RIJN, L. C. van. Principles of coastal morphology. Amsterdam: Aqua Publications, 1998.

ROSMAN, P. C. C.; VALENTINI, E. (1988) Estudo da erosão na praia de Ipanema-Leblon - RJ. Relatório COPPETEC/ ET-170.141. Cliente: Prefeitura Municipal do Rio de Janeiro IPLANRIO. Período: de 02/88 a08/88.
ROSMAN, P. C. C.; NEVES, C. F.; MELO, E. (1992) Solução conjunta dos problemas de erosão na praia de Ipanema-Leblon e qualidade de água na lagoa Rodrigo de Freitas. (Relatório Final). Relatório COPPETEC/ET-170.173 -Cliente: Prefeitura Municipal do Rio de Janeiro - IPLAN-RIO.

RUSSEL, R. D. Effects of transportation of sedimentary particles. In: TRASK, P. D. (Org.) Recent Marine Sediments. Oklahoma: Society of Economic Paleontologists and Mineralogists, 1939, p. 32-47.

SAHU, B. K. Depositional mechanisms from the size analysis of clastic sediments. Journal of Sedimentary Petrology, v. 34, n. 1, p. 73-83, 1964.

SANTANA, F. R.; NETO, A. A. Use of Seismic Attributes for Sediment Classification. The Journal of Engineering, v. 2015, n. 4, p. 134-148, 2015

SAVI, D. C. Erosão e acresção costeira na Enseada dos Anjos, Arraial do Cabo, RJ. Revista Brasileira de Geofísica, v. 25, n. 1, p. 91-99, 2007.

SAAVEDRA, L.; MUEHE, D. Dinâmica sedimentar na plataforma continental interna entre a Ilha do Cabo Frio e Cabo Búzios - RJ. In: Congresso Brasileiro de Geologia, XXXVIII, 1994. Anais. Santa Catarina, 1994.

SCHMITT, R. S.; MANSUR, K. L.; GUERRA, J. V.; GÓES, N. F. B.; SILVA, R. S.; RAMOS A. S.; MACHADO, G. M. F.; SAVI, D. C.; GERALDES, M. C.; MEDEIROS, S. R.; MORAES, J. M.; SILVA, C. B.; MATTA, P. B.; TOLEDO, P. P.; MOTOKI, A.; SICHEL, S.; GUIMARÃES, P. V.; SILVA, F. L.; PALERMO, N.; PEREIRA, R. M.; MENESES, P. T. Mapa Geológico da Folha Cabo Frio SF.23-Z-B-VI. Belo Horizonte: CPRM, 2009. CD-ROM.

SCHMITT, R. S.; TROUW, R.; SCHMUS, W. R. V.; ARMOSTRONG, R.; STANTON, N. S. G. The tectonic significance of the Cabo Frio Tectonic Domain in the SE Brazilian margin: a paleoproterozoic through cretaceous sage of a reworked continental margin. Brazilian Journal of Geology, v. 46, n. 1, p. 37-66, 2016.

SILVA, A. C. Geologia Costeira e balanço sedimentar entre os ambientes de praia e dunas - Região de Cabo Frio - Rio de Janeiro. Tese (Doutorado em Geologia), IGEO/UFRJ, Rio de Janeiro. 2009.

SILVA, M. A. M; SILVA, A. L. C.; SANTOS, C. L.; SILVESTRE, C. P.; ANTONIO, R. V.M; CUNHA, A. B. C; GRALATO, J. C. A; SOUZA, R. D. Praias da Baía de Guanabara no Estado do Rio de Janeiro. Revista Brasileira de Geomorfologia, v. 17, n. 2, p. 205-225, 2016. 
SHORT, A. D. Handbook of beach and shoreface morphodynamics. Chinchester: John Wiley \& Sons Ltd, 1999.

TOMMASI, L. R. Nota sobre os fundos detríticos do circalitoral inferior da plataforma continental brasileira ao sul do Cabo Frio. Boletim do Instituto Oceanográfico. v. 18, n. 1, p. 55-62, 1969.

TAVAres, A. C. A.; BUlhÕES, E; ESTRADA, A. F. D. Distribuição de fácies sedimentares e tendências de transporte de sedimentos na enseada de Manguinhos, Armação dos Búzios, RJ. Revista de Geografia (Recife), v. 27, n. 2, p. 81-96, 2010.
VERA-CRUZ, D. Artificial nourishment of Copacabana beach. In: Coastal Engineering Conference, XIII, 1972. Proceedings. New York: American Society of Civil Engineers, 1972, p. 1451-1463.

UNESCO. Principles of geological mapping of marine sediments. Unesco Reports in Marine Science. 1986.

WENTWORTH, C. A. Scale of Grade and Class Terms for Clastic Sediments. Journal of Geology, v. 30, n. 5, p. 377-392, 1922. 